\title{
Technologies, Challenges and Needs of K-12 Teachers in the Transition to Distance Learning during the COVID-19 Pandemic
}

\author{
Gregory M. Francom ${ }^{1}$ (D) $\cdot$ Sang Joon Lee ${ }^{1} \cdot$ Halle Pinkney ${ }^{1}$ \\ Accepted: 31 March 2021 / Published online: 26 June 2021 \\ (C) Association for Educational Communications \& Technology 2021
}

\begin{abstract}
In response to the COVID-19 pandemic, K-12 schools in the United States closed and teachers transitioned to distance learning. The purpose of this survey research study is to determine technology resources and strategies K-12 teachers have used in this transition. Additionally, this study examines the difficulties teachers experienced, along with support they wish they had during the transition. Findings indicate that a wide variety of websites and applications were used to provide academic continuity, the majority of which were familiar to teachers. In the transition process, teachers were faced with various challenges, including difficulty engaging students and parents, a lack of school/district guidelines, and student Internet and computer access issues. Recommendations to prepare for future emergencies include making clear plans for emergencies and incorporating online components and training within current face-to-face classes and professional development.
\end{abstract}

Keywords COVID-19 $\cdot$ Emergency $\cdot$ Distance learning $\cdot$ K-12 $\cdot$ Online learning $\cdot$ Pandemic $\cdot$ Teachers

In response to the unprecedented COVID-19 pandemic, K-12 schools in the United States closed and teachers were asked to transition their courses online. Many teachers were unprepared for this transition and faced great challenges for delivering quality instruction in an online format. The current pandemic gives teachers and administrators a chance to evaluate the readiness of schools for distance education and increase readiness for future emergency situations.

Because the current COVID-19 pandemic is unique, few studies have examined how teachers transition to distance learning in an emergency. Currently, it is important to understand what websites and applications teachers used to convert their classes for distance learning, what strategies they adopted to learn about technology-based solutions, and what challenges they encountered. In addition, it is important to know what support

Gregory M. Francom

greg.francom@msstate.edu

Sang Joon Lee

slee@ colled.msstate.edu

Halle Pinkney

hpinkney@ colled.msstate.edu

1 Mississippi State University, 2208 Plum Road, Starkville, MS 39759, USA teachers wish they had to help them during the transition. This information will help teachers, technology support staff, and administrators better respond to similar challenges in the future.

\section{Literature Review}

School closings for localized catastrophic events such as weather events, protests, and disease outbreaks are unfortunately somewhat common (Bates, 2013; Wong et al., 2014). The good news is that these closings are usually temporary and localized in nature, and as a result do not require distance learning to keep students connected (Wong et al., 2014). In fact, in a two-year (2011-2013) study of unplanned school closures, Wong et al. (2014) found that most unplanned school closures are due to weather and natural disasters.

In uncertain and emergency situations, educational opportunity can do much more than provide learning opportunities to students. It can help to sustain mental and physical wellbeing and offer stability and hope for the future (INEE, 2004). Distance learning methods are therefore essential in situations where face-to-face instruction cannot continue (Creed \& Morpeth, 2014; Hanssen \& Rana, 2007; Laprairie \& Hinson, 2006). In the midst of the COVID-19 pandemic, K-12 school district leaders were forced to develop plans for distance 
learning because it was difficult to tell when regular face-toface instruction could resume.

Though the literature is sparse concerning academic continuity during pandemic events, there are some written suggestions to help plan for academic continuity during emergency events in general (see Bates, 2013; Creed \& Morpeth, 2014; Laprairie \& Hinson, 2006). These suggestions show that educational institutions benefit greatly from emergency management plans to support academic continuity in situations like the current pandemic (Bates, 2013; Laprairie \& Hinson, 2006; Wong et al., 2014). In order to keep students from falling behind academically, institutions must develop strategies to respond to crisis events that make face-to-face instruction impossible (Bates, 2013). Despite the need for preparation, a review of the literature reveals that many K-12 institutions are not prepared for academic continuity in the face of a pandemic. In one study conducted during a flu outbreak, Duford (2008) discovered that few school superintendents knew who had the authority to close schools in the case of a pandemic emergency. A similar study of New York City K-12 Principals found that over $84 \%$ of schools had no plan for a pandemic, and $80 \%$ of principals in schools that did have a pandemic plan were not familiar with it (Thomas et al., 2007).

Whatever their level of preparation, during the current COVID-19 pandemic many K-12 teachers who are used to teaching only face to face are being forced to quickly transition to online learning on an emergency basis (Butcher, 2020). The type of pre-planned and carefully developed online learning that takes place under normal circumstances is not happening because of time and resource constraints (Hodges et al., 2020). Hodges et al. (2020) have used the term "emergency remote teaching" (ERT) to describe the hastily prepared online learning that is happening because of the pandemic. Though the COVID-19 pandemic is unique in its scope, there have been prior studies of faculty experiences where ERT was necessary both in higher and K-12 education.

\section{Emergency Remote Teaching in Higher Education}

An earthquake event that shut down face-to-face classes at a university is described in studies by Mackey et al. (2012) and Tull et al. (2017). Mackey et al. broke down the process of returning to academic continuity into four phases of faculty activity, including: (a) react, recover and redesign; (b) restart; (c) reconsolidate, and (d) review and reflect. During the react, recover and redesign phase, the university administration and faculty had to re-establish communication with students and then begin the redesign process to put courses online (Mackey et al., 2012; Tull et al., 2017). Many faculty members did not feel ready to teach fully online, and had to work hard to learn and prepare for online learning. As a result, some faculty formed their own informal support groups to share information about online learning technologies and practices (Tull et al., 2017). The restart phase consisted of restarting the teaching process with students whether in newly reestablished physical classrooms or online. During the reconsolidate phase, earthquake aftershocks occurred, forcing faculty to adopt more relaxed attendance requirements and allow students to choose between online and face to face learning depending on their needs (Mackey et al., 2012). In the review and reflect phase, the university had recovered from the earthquake, yet some faculty still used online teaching tools and practices adopted during the recovery (Mackey et al., 2012; Tull et al., 2017). Based on this experience, the researchers have suggested that all face-to-face courses should have online components already in place for when an emergency happens, so that academic continuity can be provided during short-term disruptive events (Bates, 2013; Tull et al., 2017).

Czerniewicz et al. (2019) studied faculty perceptions during the emergency closure of higher education institutions in South Africa. Interviews revealed that faculty felt prepared to teach online to the extent that they had already used online technologies in face-to-face classes. In this experience, staff at the university were inundated with a high workload as they supported faculty and students in their teaching and learning efforts (Czerniewicz, 2020; Czerniewicz et al., 2019).

\section{Emergency Remote Teaching in K-12 Education}

In the area of K-12 education, a literature review reveals one relevant research study of faculty experiences with ERT. Fox (2004) shared the experiences of a group of eight K-12 teachers who had to support ERT during school closures in Hong Kong due to a SARS epidemic. In this situation, the level of instruction provided to students varied greatly because there were no clear guidelines on how much teaching and learning should continue to take place. Most teachers in this study struggled to teach online for a variety of reasons (Fox, 2004). First, there was a gap between the training that had previously been provided to teachers - which was focused on face-to-face teaching - and the online teaching that they were being required to do during the pandemic (Fox, 2004). Also, once classes went online, most of the students were absent or lurking in online activities and sessions. There was also a feeling among faculty that their students did not fully understand how to learn in an online environment (Fox, 2004). Fox concluded that teachers needed more clear guidelines about how much teaching and learning should happen, more training specifically for online learning practices and technologies, and a better understanding of the affordances of potential online learning technologies.

\section{Preparing for Distance Learning}

Some key suggestions for faculty who are preparing for ERT can be found in the literature. First, a plan should be in place for leveraging online learning in the case of an emergency 
(Bates, 2013; Duford, 2008; Laprairie \& Hinson, 2006). As delineated in this plan, it is important for schools to ready a communication channel to provide students, faculty and stakeholders with timely updates on emergency situations (Czerniewicz et al., 2019; McLennan, 2006; Tull et al., 2017). Faculty should also be prepared in advance to understand and use blended and online learning practices and tools (Mackey et al., 2012; Tull et al., 2017). Students also will need to be able to understand the greater burden of responsibility that they receive when learning remotely, and administrators and faculty should expect some students to have lower access to the Internet and computers for online learning than others (Czerniewicz, 2020; Fox, 2004; Mackey et al., 2012). Finally, each face-to-face class should have online components already in place for when an emergency makes it necessary for classes to go fully online (Bates, 2013; Mackey et al., 2012; Tull et al., 2017). It is likely that schools that have followed these guidelines are responding to the challenges of the current pandemic more effectively than schools that have not.

\section{Purpose of this Study}

The purpose of this survey research study is to gain a clear picture of how K-12 teachers have transitioned to distance learning during the COVID-19 pandemic. This study addresses the following questions:

1. What websites and applications have participants used to support distance learning as a result of the pandemic?

2. What strategies have teachers used and what difficulties have they encountered when shifting to distance learning?

3. What support do teachers wish they had in adapting to distance learning?

\section{Method}

During widespread school closures in the United States due the COVID-19 pandemic, a survey was sent to email lists of teachers in the states of Mississippi and South Dakota $(N=$ 15,341). These two states were chosen for the study because the researchers had working ties to teachers in those states. Teacher email addresses were systematically gathered from available school websites in both states, therefore, teachers whose email addresses were not available on a school website were excluded from this study. The web-based survey link was sent out via email in May 2020, after the pandemic forced schools to close and move their courses online. Follow up emails were also sent later to encourage participation. All research materials and procedures were approved by the institutional review board of the researchers' university.

\section{Instrument}

The survey included 13 questions asking about distance learning websites and applications being used, strategies used to quickly gain knowledge about distance learning options, difficulties encountered in transitioning to distance learning, and assistance needed when preparing for distance learning and tools and practices. Additionally, the survey items featured demographic information such as students' Internet access and computer availability for distance learning, teachers' teaching experience, grades, subject areas, and 1:1 classroom (see appendix). The focus of the survey was on distance learning practices adopted in the transition from face-to-face to online learning. Items in the survey were informed by the literature on the adoption of technology tools and resources among K-12 teachers, and the researchers' experience working with K-12 teacher technology use. For instance, there are a variety of documented barriers to technology use in K-12 education (e.g., Daoud et al., 2020; Ertmer \& Ottenbreit-Leftwich, 2010; Kopcha, 2012), and also general studies about the tools and resources that teachers use for both online and face-to-face teaching and learning (e.g., Howley et al., 2011; Rice, 2012; Ruggiero \& Mong, 2015). Ideas from these studies were incorporated into the survey items when they were deemed applicable to the issues teachers were facing in the COVID-19 pandemic.

\section{Data Analysis}

For open-ended survey questions, qualitative content analysis methods were used to determine patterns and themes in similar responses. Examples of these questions include "how is learning happening," "what strategies did you use to quickly gain knowledge about new websites and applications," and "what kind of help do you wish you would have had as you prepared to support distance learning?" Quantitative descriptive statistical methods were used on the other survey questions about LMSs used, websites and applications used, and difficulties encountered. These questions were also analyzed for factors using demographic responses earlier in the survey such as state, grade level, teaching experience, 1:1 classroom, and percentage of learning still happening. Additionally, a chisquare test of independence was conducted to see whether there were any differences for difficulties encountered between teachers in South Dakota and Mississippi.

\section{Results}

A total of 388 valid responses were collected in this survey. Out of this total, $52 \%$ come from Mississippi, 39\% come from South Dakota and 10\% did not specify their state. Teaching experience ranged from 1 year of experience to $20+$ years. Lower elementary teachers make up $13 \%$ of the respondents, 
while $11 \%$ teach in upper elementary grades, $18 \%$ teach middle school, and $38 \%$ teach high school. Respondents teach in many different subject areas including music, math, science, social studies, English/language arts, technology/computer science, etc. A full $62 \%$ of respondents indicated that their classroom was 1:1 (featuring a tablet/computer for each student) while $38 \%$ indicated that their classroom was not. When asked about the percentage of their students who had Internet and computer access sufficient for learning, participants shared that $66 \%$ had Internet and $65 \%$ had computer access.

\section{How Learning Is Still Happening}

Respondents indicated that learning was still happening through various methods even after schools were closed. One common type of learning was review work, which covered subjects such as math, reading, writing, spelling and even life skills. Teachers were also using videos, journals, projects, research papers, and quizzes/tests to continue with the learning. A variety of subject areas were represented in this question. For example, one physical education teacher stated, "I have sent out activities to get their heart rate up." A music teacher also responded saying "Students submit music performance and auditions through video." These responses show that teachers from a variety of subject areas sought innovative ways to encourage participation and learning.

Some of the responses to this question revealed teachers' opinions about types of students still learning. For example, one teacher's response to the question stated that "Those who want to do well on their ACT next year are working, and those who have parents who care about their education." Another teacher shared, "The ones that worked willingly when school was open are still working."

\section{Websites and Applications Used to Communicate}

The top 10 websites and applications used to communicate with students included Google Classroom, Zoom, email, Remind, Canvas, School Status, ClassDojo, Google Meet/Hangouts, YouTube, and Schoology (see Fig. 1). However, teachers also mentioned a wide variety of other applications and websites, from additional learning management systems (LMSs), to basic communication tools (such as texting, google voice, phone calls), to video and screencast applications (including Screencastify, Screencastomatic, and EdPuzzle) to general drill and practice or tutorial websites (like iReady, Khan academy, IXL, MobyMax, and BrainPop).

\section{Websites and Applications Used to Accept Student Work}

For this question, many of the same websites and applications were mentioned, and again a wide variety of these resources were listed. The top 10 websites and applications mentioned include LMSs (including Google Classroom, Canvas, Schoology), Email, Google Apps for Education, iReady, Seesaw, messaging apps (including Remind and texting), and Zoom (see Fig. 2). In addition to the top 10 websites and applications mentioned, there were a variety of other websites and applications used during the pandemic, showing a diversity of use among educators. These
Fig. 1 Websites and Applications used to Communicate with Students

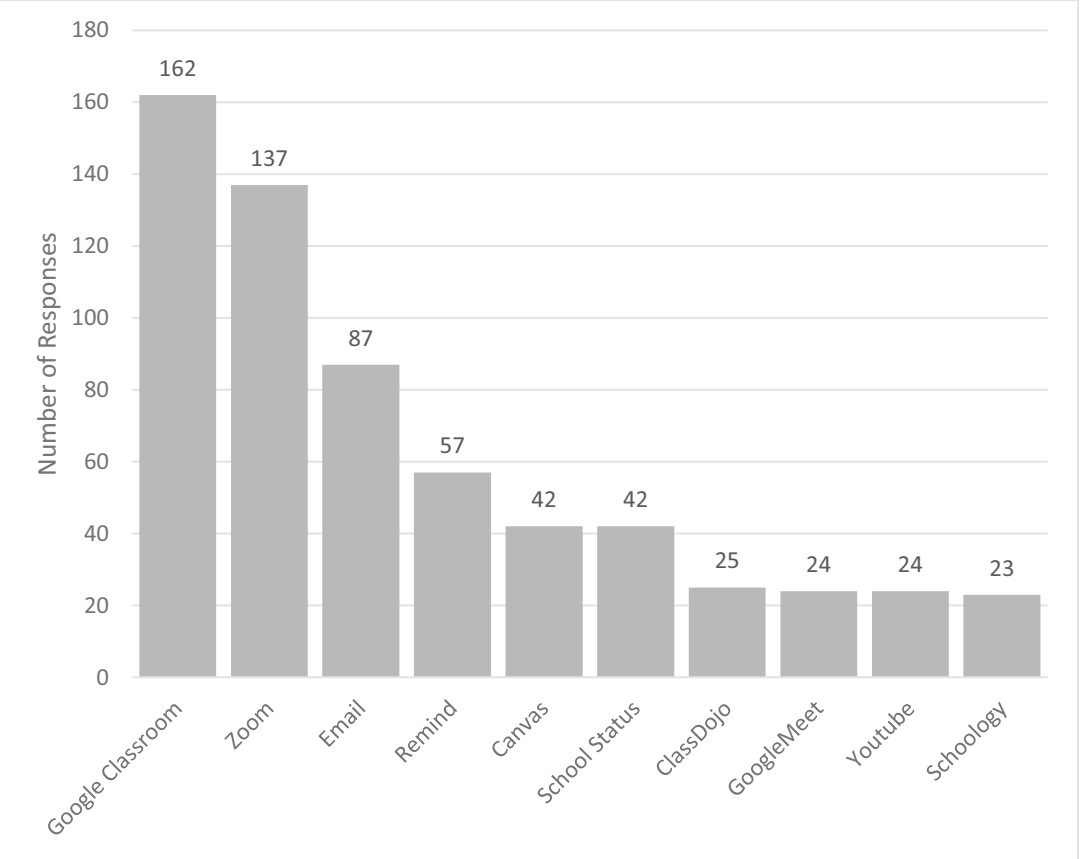


Fig. 2 Websites and Applications used to Accept Student Work

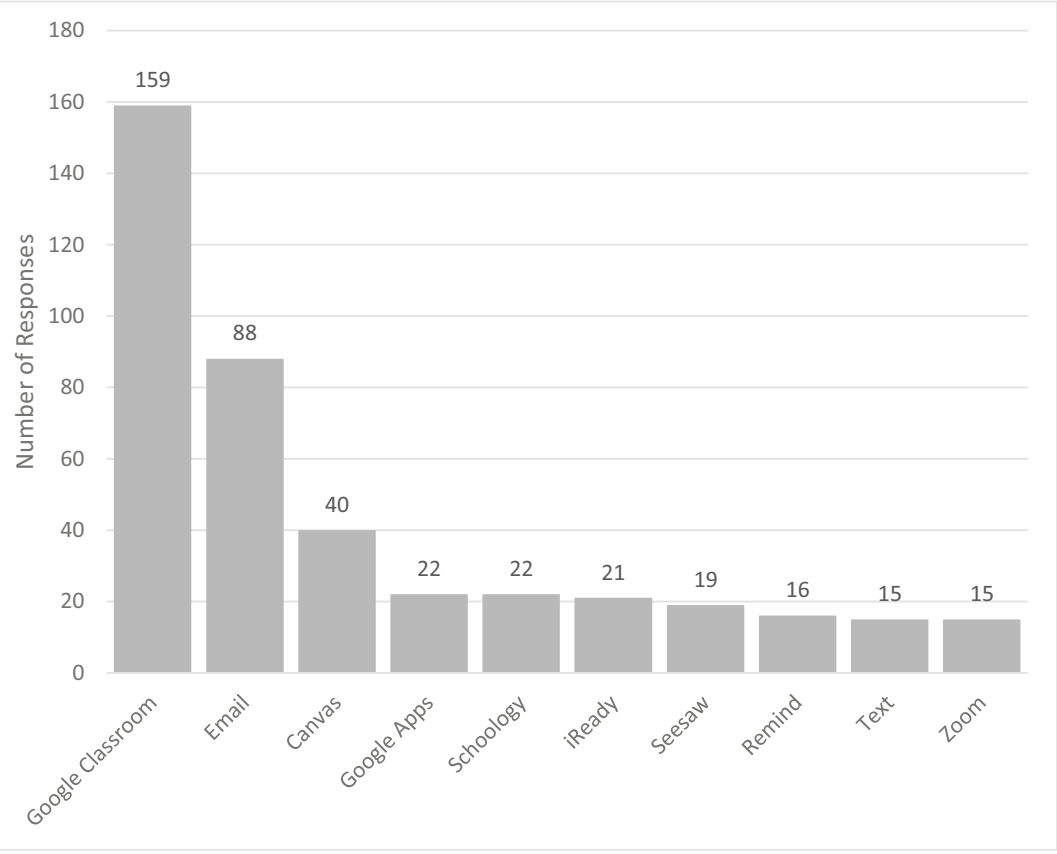

applications ranged from tutorials (Khan Academy, IXL, MobyMax), video sharing sites (Flipgrid, EdPuzzle) and literacy sites (CommonLit, ReadWorks) to other communication and assessment tools (ClassDojo, NearPod, Quizziz) and even paper-based assignments.

Overall, a wide variety of websites and applications were used by teachers as they adjusted to the pandemic. When asked about how many of the websites and applications were new to them, teachers indicated that on average only $26 \%$ of these websites and applications used during the pandemic were new to them.

\section{Learning Management Systems Used}

Participants responded to questions about the LMSs used before and after the pandemic broke out. Google Classroom was
Fig. 3 Learning Management Systems used Before and During the Pandemic

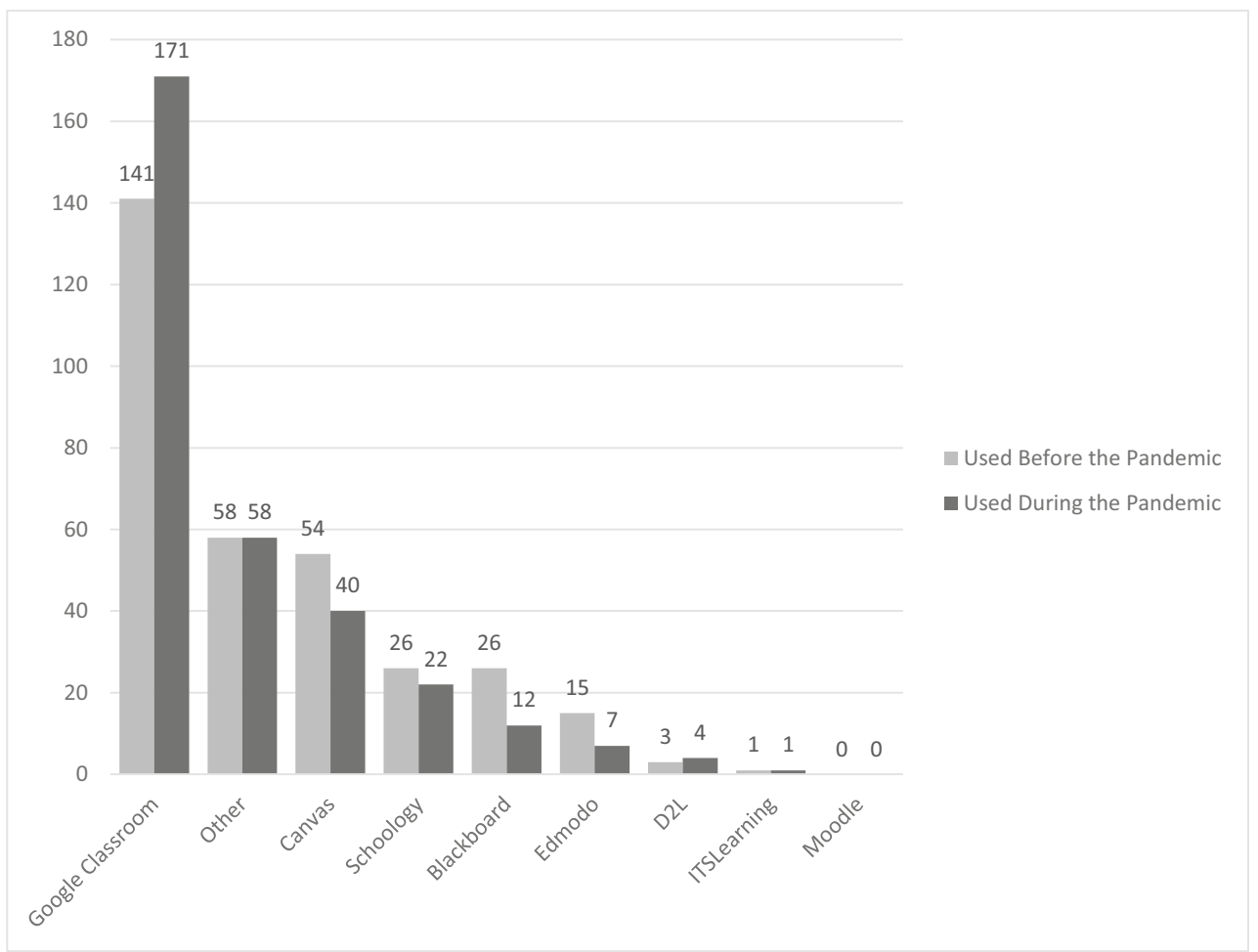


the top LMS before the pandemic, and the most highly used LMS during the pandemic (see Fig. 3). Use of Canvas, Schoology, Blackboard and Edmodo were reduced during the school closures. While interpreting these results, it is important to remember that for some respondents, teaching may have completely discontinued during the pandemic.

A final survey question on LMSs allowed respondents to indicate the ways in which the LMS was being used to support learning. Responses indicated that LMSs were primarily used to facilitate the submission and grading of assignments, followed by sharing learning materials, sharing videos and providing announcements and updates (see Fig. 4).

\section{Strategies Used to Gain Knowledge about Websites and Applications}

When faced with new challenges for supporting distance learning during the pandemic, many teachers took advantage of technology-supported solutions and self-teaching. Teachers used YouTube tutorials, independent google searches for information, trial-and-error and reaching out for help from other teachers as their main strategies for gaining knowledge. One teacher stated, "I did not have a Google Classroom before this, but I had been to a couple intro workshops on it [...] SimpleK12 offered free webinars and they helped a lot." Many teachers supplemented their web searches and selfteaching with online forums through sites such as Facebook where they were able to communicate with teachers from all over. One teacher said, "I joined a couple online forums/ groups (mainly on Facebook) to hear what other teachers are using to help."

Fig. 4 How Learning Management Systems are Being used to Support Learning
Table 1 Top 5 practices and tools that teachers plan to use after the pandemic

\begin{tabular}{lll}
\hline Teaching Practices/Tools & Frequencies & Percentage \\
\hline Learning management systems & 156 & $49.1 \%$ \\
Online resources & 97 & $30.5 \%$ \\
Communication & 75 & $23.6 \%$ \\
Web conferencing & 69 & $21.7 \%$ \\
Screen, video, audio recording & 58 & $18.2 \%$ \\
\hline
\end{tabular}

In addition, some teachers also received help from their district or state. For example, one teacher commented, "Our school district quickly sent out information to us as well as websites and application ideas daily." Not all interaction with district support was helpful, however, and some teachers mentioned difficulties with district support and restrictions. For instance, one teacher shared, "I researched Zoom and had one meeting with students before the district banned the meetings."

\section{Teaching Practices and Tools that Will Continue to Be Used}

Many teachers indicated a desire to continue using online teaching practices and tools even after the pandemic is over (see Table 1). A high school science teacher wrote, "All of them have unique features that have been really helpful to accomplish what I needed them to [...] I think I will continue using all of them in some way." Another teacher said, "I will

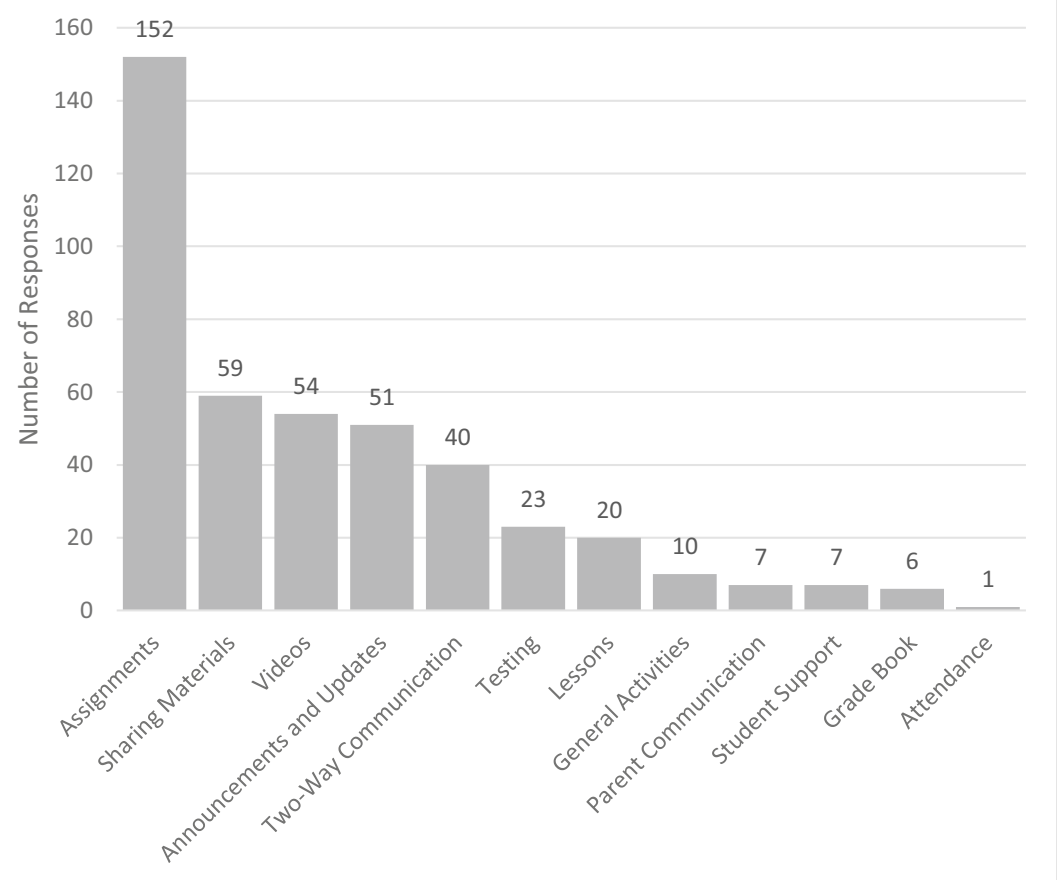


be incorporating almost all of what I have learned into classroom teaching. It will allow me to differentiate instruction much more efficiently." One teacher believed, "I will be a better teach $[$ sic $]$ after this."

Almost half of the respondents plan to keep using their LMS after returning to face-to-face instruction. A full $30 \%$ of teachers also plan to use many online resources available for their subjects, including video sharing sites like YouTube and Khan Academy and other online learning sites such as IXL, MobyMax, iReady, ReadWorks, CommonLit, and Epic.

Many teachers also indicate that they will continue using communication tools and practices when school opens up again. Remind, ClassDojo, GroupMe, and Seesaw are some of the applications teachers mentioned they would continue to use. One teacher wrote, "I will say my parent communication skills have increased dramatically over the course of the past month or two, that should be a boon whether we're in a traditional or online setting in the future."

About $21 \%$ of teachers plan to continue using web conferencing tools like Zoom and Google Meet to support virtual field trips, guest speakers and participation by absent students. About $18 \%$ of teachers who created their own videos using screen and video capture tools like Screencastify, Loom, and Flipgrid also showed an interest in continuing to use these tools for lectures, tutorials, and assignments. One English teacher explained the rationale for continuing to use these tools, "students said they liked to be able to 'hear' the information more than once and pause my video so they could think and write."

\section{Greatest Difficulties Encountered}

Teachers encountered many difficulties while transitioning to distance learning. There were 350 valid responses to this open-ended question and these responses were coded for analysis. Table 2 shows the top 10 difficulties that teachers mentioned.
These initial top 10 codes on difficulties were categorized into five areas: students (44.0\%), remote teaching (36.9\%), technology (34.6\%), parent involvement and home environments (10.6\%), and school district and administration (4.3\%). Each of these areas will be discussed.

First, teachers found that it was difficult to contact and communicate with students, get them participating and motivated, keep them engaged, and make them accountable for their learning. Reaching out to students through technology was difficult, and some students also showed a lack of interest in schoolwork. One high school teacher said, "The greatest difficulty was to reach all of the students and get them to participate and complete assignments." Even if students joined a live session, it was hard to know whether students were engaged in learning. One math teacher wrote, "The lack of instantaneous feedback to and from students has been the biggest downside to my current model." Additionally, teachers felt that many students were not ready for distance learning. Another math teacher mentioned, "My students as a whole were not very computer literate [...] I feel like I had to begin by teaching them how to turn on the computer."

Second, setting up a distance learning course, finding and creating online resources, monitoring student progress and providing instructional support were challenging in distance learning. Many teachers felt that they had limited knowledge and skills for distance learning and thus had to learn new things on the fly. One teacher wrote that the greatest difficulty was "The frustration of learning to understand how to organize a Canvas course in an attractive and user-friendly way." Many teachers also mentioned the lack of time to prepare distance learning and grade student assignments. One English teacher wrote, "No time to plan. We closed school on a Friday, heard nothing, and then had 24 hours to get a distance learning plan to our students." Since teachers had to stay home and work, they had to balance instructional time with family needs. One high school science teacher wrote that it was difficult, "finding the time to prepare my lessons and

Table 2 Top 10 difficulties that teachers encountered in distance learning

\begin{tabular}{lll}
\hline Code & Frequency & Percentage \\
\hline Internet/computer access & 108 & $30.9 \%$ \\
Participation/motivation/engagement/accountability & 80 & $22.9 \%$ \\
Contact to/communicate with students & 53 & $15.1 \%$ \\
Parent involvement/Home environments & 37 & $10.6 \%$ \\
Course setup \& conversion/online resources & 34 & $9.7 \%$ \\
Limited knowledge/skills/learning new & 28 & $8.0 \%$ \\
Time & 26 & $7.4 \%$ \\
Monitor/feedback/instructional support & 26 & $7.4 \%$ \\
Teaching styles/subjects & 20 & $5.7 \%$ \\
Student readiness for distance learning & 17 & $4.9 \%$ \\
\hline
\end{tabular}


convert them into a digital format while also trying to entertain my OWN children and help them with their own learning."

Third, Internet and computer access was a significant challenge for teachers working to support distance learning. A middle school science teacher said, "I work for a rural area where I have spotty internet service and many of students do not have computers and/or internet access to complete anything I was creating." Another teacher commented, "Some students do not have access to good online connections [...] they have to drive closer to populated areas or to the front of a school to get on Wi-Fi." For this reason, some teachers had to prepare both paper packets and online assignments.

Fourth, teachers noticed a lack of parent involvement and support. Since many students were not motivated or prepared for online learning and it was difficult for teachers to contact and engage them without support from parents. Many teachers were not able to communicate with parents, or realized that parents could not provide support needed for their children. A high school English teacher said:

I was confronted many times with parents who were totally unprepared to provide a structured environment for their students to learn. I was told, "I can't make them do it," "It doesn't count anyway," "I don't believe the students should be forced to work on schoolwork right now," "They are going to pass anyway, so I am not going to fight with them."

Lastly, teachers experienced school and district leadership issues. Primarily, teachers were confused about what they should do after converting to distance learning. Many teachers felt that they did not have a clear understanding of expectations for class meetings, learning resources, student performance, and grading. A middle-school English teacher wrote:

There also was little guidance provided by administration, and we did not meet as a staff prior to or during the school closure [...] determining what to assign, how much to assign, and how to approach assessment and/ or grading were also areas I wrestled with.

In addition, some schools did not allow teachers to hold online sessions or teach new content. Other schools limited access to websites like YouTube, which teachers could have used to provide online learning resources.

Although many teachers in the two different states shared similar difficulties, there were differences between teachers in South Dakota and Mississippi. As shown in Fig. 5, a majority of teachers in South Dakota were worried about how to motivate and engage students in distance learning, yet a majority of teachers in Mississippi had concerns about adequate Internet and computer access for students. A chi-square test of independence showed that there was a statistically significant difference in responses about access between the two states $\left[\chi^{2}(1)=29.29, p<.001\right]$.

\section{Help Teachers Wish they Had}

Respondents to this open-ended question indicated that knowledge and skills in using technology, student Internet and computer access, more time for preparation, and better guidance would have helped them effectively make this transition (see Table 3 ). Only $10.3 \%$ of teachers felt that they were prepared or fully supported during the transition.

A full $27 \%$ of teachers wished they had previous training or professional development on learning management systems, digital tools, online resources, and distance learning. One teacher wrote:

I wish I had more training on the technology needed for this type of teaching [...] I wish I had used it with my students in the classroom before distance learning came to be, it would have made everyone's lives easier.

Another teacher responded similarly, saying "I wish we could have had more training on the platform we used: Google Classroom, and that the students would have had some kind of practice with it before this all happened."

Fifty-six teachers (19.9\%) wished that students had adequate Internet and computer access. A Mississippi high school teacher wished for "a way to get affordable service to students who didn't have any AND a way for them to check out a laptop to use." A South Dakota teacher also shared, "It would have been ideal for each student having an iPad or laptop or computer to use, along with internet access."

Many teachers discussed the lack of time to prepare for distance learning. One teacher wrote, "I wish I would have just had time to prepare something better [...] we had the weekend to get things up and running so it was learn-asyou-go." Also, teachers wished that they would have had clear guidance on what platforms and tools to use, appropriate level of student workload, grading, and attendance to make sure all teachers were on the same page. A PE teacher wrote, "I think having guidelines/expectations [...] would have been nice. It feels either like I'm doing way too much, or maybe not enough at other times." Another English teacher mentioned, "Our district was not clear about expectations and changed guidelines several times in the first few weeks [...] that caused a lot of stress with what to use or not use online."

Additional help items that teachers mentioned they could have used included teaching resources available for distance learning, more parental support and involvement, previous experience using technology, tech support, ways to communicate with students, and collaboration with other teachers. 


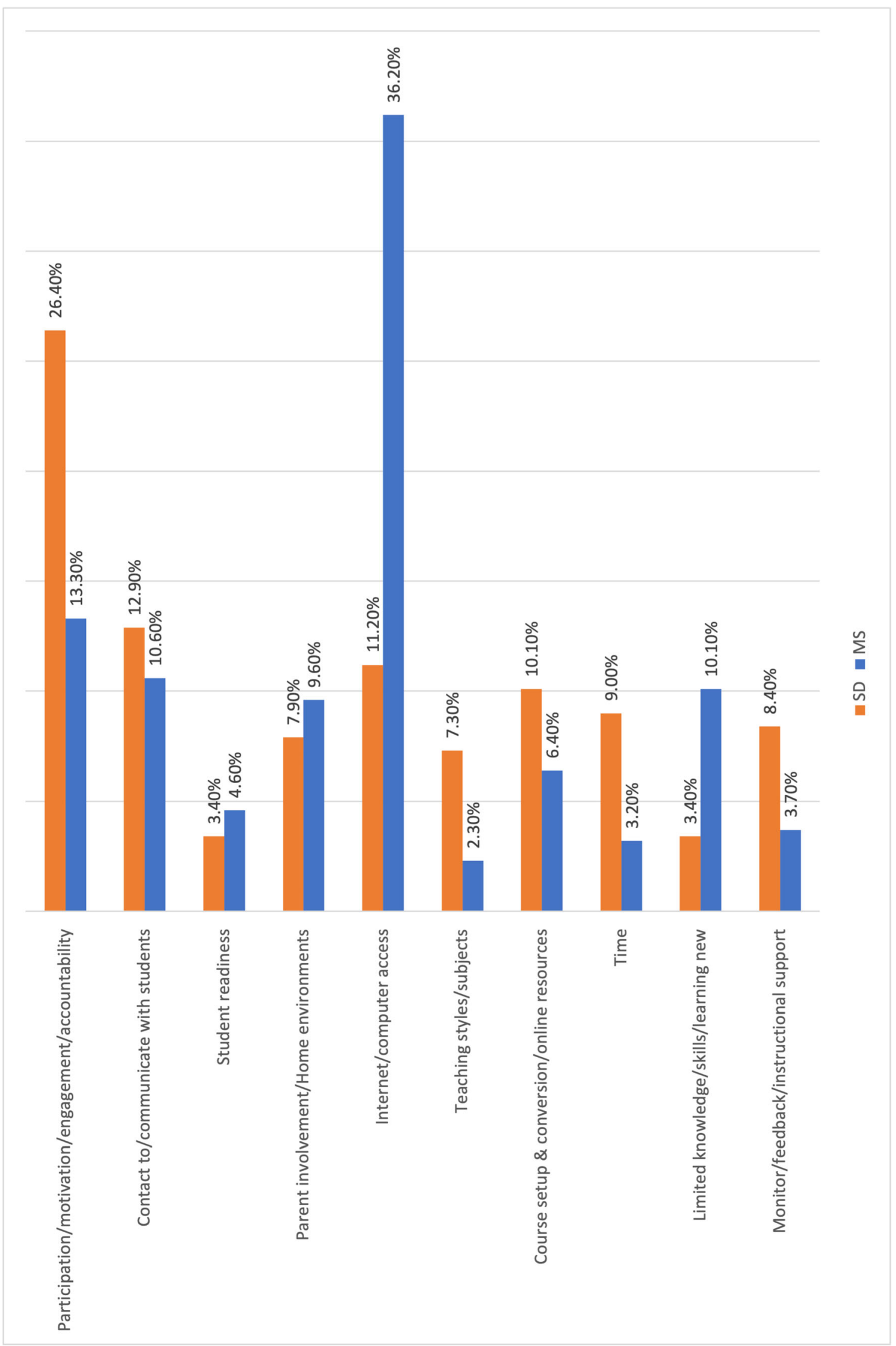

Fig. 5 Top 10 greatest difficulties mentioned by teachers in SD and MS 
Table 3 Help that teachers wish that they would have had to transition to distance learning

\begin{tabular}{lll}
\hline Code & Frequency & Percentage \\
\hline Information/Instruction/training/PD & 76 & $27.0 \%$ \\
Access to Internet/computer & 56 & $19.9 \%$ \\
More time/preparation & 41 & $14.5 \%$ \\
Policy/guidance/plan/grading & 38 & $13.5 \%$ \\
Teaching resources & 22 & $7.8 \%$ \\
Student readiness & 22 & $7.8 \%$ \\
Parental support & 18 & $6.4 \%$ \\
Previous experience/tech integration & 18 & $6.4 \%$ \\
Tech support/tools & 14 & $5.0 \%$ \\
Ways to communicate & 12 & $4.3 \%$ \\
Collaboration & 12 & $4.3 \%$ \\
\hline
\end{tabular}

\section{Discussion}

The results from this study show how teachers have responded to the challenge of transitioning to distance learning during the COVID-19 pandemic. Many websites and applications were used to facilitate the learning process among students, yet the majority of these were already familiar to the teachers who adopted them. This finding is in line with the experience described by Czerniewicz et al. (2019) in which most teachers felt prepared to teach to the extent that they already knew the technology tools required. In the current study, few teachers felt like they were prepared to make the shift to distance learning. With little time to learn, teachers primarily used those websites and applications with which they were already familiar. These results underscore the importance of ongoing technology professional development opportunities for teachers.

In this study, teachers exhibited ingenuity in the ways that they gained knowledge of websites and applications by using online resources and social media networks. These approaches are similar to those mentioned by Tull et al. (2017) in which teachers setup their own online communities to share information. However, this study also showed that teachers' learning and adoption of new websites and applications can only go so far if school and district leadership and policies disallow adoption of such tools.

This study has also indicated that a significant group of students may still not have Internet and computer access sufficient for distance learning. Previous studies show a positive correlation between home Internet access and school performance (Bauer et al., 2020; Daoud et al., 2020). Ertmer and Ottenbreit-Leftwich (2010) discuss how first-order barriers to teacher technology use have been reduced in the classroom as more technologies become available for use. However, it appears that these first-order barriers for teachers and students alike still exist at home and can significantly reduce the opportunity for students to learn online, especially in rural areas (Howley et al., 2011; Sundeen \& Sundeen, 2013). In the current study, the perception among teachers was that the gap between students with and without Internet and computer access also served to increase the gap between low and high performing students. This concern was also raised in Czerniewicz's (2020) discussion of a university shutdown in which inequities in student learning resulted from inequities in technology access.

Teacher comments from this study indicate that a possible unanticipated benefit of the pandemic is continued use of adopted websites and applications even when normal school resumes. Similar benefits were found in previous studies of university shutdowns in which teachers continued to use the tools they had adopted during the shutdown (Fox, 2004; Mackey et al., 2012; Tull et al., 2017). This continued use of new technologies could lead to long-term benefits for learning by enhancing communication between teachers and students/ parents and supporting efficient management of assignments and content.

Student participation and engagement continue to pose significant issues for distance learning (Barbour et al., 2015; Fox, 2004). In the current study, teachers faced great difficulties communicating with students, getting them to participate and stay engaged, and making them accountable for their learning. During the pandemic, some schools and districts were not ready with a plan to effectively support student learning from a distance, and therefore could not enforce requirements for students to participate or submit assignments. There was also a lack of clear guidelines for teachers about recommended technology tools, student learning workload, and attendance expectations. In a previous study, Fox (2004) describes similar experiences in which there was a high variability of workload for both teachers and students due to the lack of clear school/district guidelines. In the current pandemic, the lack of school or district plans was likely a significant factor leading to wide differences in learning activity from class to class.

Similar to findings in Fox (2004), students and their parents in the current study were unprepared to take upon the higher level of responsibility that comes with distance learning. Many students did not have much experience with technology, and this study suggested that it was challenging to teach them how to manage their own distance learning via technology. Teacher comments also indicated that parents were unable to or did not want to create a structured environment for learning. Parent involvement in education remains an important factor in the quality of student learning (Anderson \& Minke, 2007), yet there is evidence in this study that some parents will offer resistance to learning activities that teachers implement. 


\section{Limitations}

Limitations of this study stem from the low response rate among potential respondents from the states in the study. The low response rate was likely a result of the timing of the survey, which occurred right in the semester in which the COVID-19 pandemic had made drastic changes to teachers' work. Because of this, caution should be used when interpreting the results of this study.

\section{Conclusion}

The recent COVID-19 pandemic led to widespread school closures, forcing many teachers to adopt distance learning practices and tools in order to provide academic continuity. In times of uncertainty, educational opportunity becomes even more important because it can sustain mental and physical well-being along with hope for the future (INEE, 2004). Therefore, distance learning methods become essential to support academic continuity (Creed \& Morpeth, 2014; Laprairie $\&$ Hinson, 2006).

School districts need to plan for the possibility of shifting from face-to-face to distance learning. The plan should include actions to take based on different severities of emergency situations and explain how much learning should happen, what technologies teachers should use, and what standards students should be held to (Fox, 2004). These plans should be communicated to parents and students as well as the greater school community. Teachers in the current study stressed the importance of regular quality communication with parents as they strived to support learning at home. Parents should be guided on how to support their children's learning and how to provide a structured environment at home that is conducive to learning. Some states already require students to take an online course before they can graduate (Etherington, 2017). This approach may better prepare students and parents for the rigors of online learning when it becomes necessary. Any district plan will also need to consider the level of computer and Internet access that students have at home, and seek to mitigate circumstances in which only some students have full computer and Internet access for learning.

Prior to the pandemic, most technology professional development opportunities for teachers have been focused on supporting face-to-face learning in the classroom (Fox, 2004; Liao et al., 2017). The experience of the pandemic must change our thinking to support models of learning not based on time in the classroom, but on more flexible learnercentered education opportunities that are both online and face to face (Fox, 2004; Mackey et al., 2012). Many notable efforts to redesign schools have led to more opportunities for learner- centered models of education that are compatible with distance learning (see Reigeluth \& Karnopp, 2013). These methods are focused more on student learning in whatever circumstance and less on time in a classroom, and are made possible and necessary by current technological and societal advances. Professional development that fits within these new models could cover setting up routines and technology tools for learning during the first weeks of class and then transitioning to exclusively online learning that continues these routines as the need arises. In addition, future professional development opportunities could support teachers in helping students to take better ownership of learning using technological tools and resources (see An \& Reigeluth, 2012; Reigeluth et al., 2016).

Finally, in uncertain times that require a more blended learning approach, school and district technology leadership must adopt an open attitude toward new technological tools and resources. Overly-prohibitive policies that block or disallow the use of potentially useful websites and applications will need to be relaxed so that teachers can adopt and use new technology tools to support learning (Francom, 2016). With these changes in mind, schools can be better prepared for academic continuity during future school closings, whether because of the current COVID-19 pandemic or for other emergencies.

\section{Appendix}

\section{Survey Instrument Items}

- Your current primary role at your school

- Your school district name

- Your years of teaching experience (round to the nearest year)

- $1-5$

- $6-10$

- $11-15$

- $16-20$

- More than 20 years

- Grade levels that you teach

- Subject areas that you teach

- Would you consider your classroom(s) to be one to one? (a one-to-one classroom always has a computer or tablet available for each student)

- Yes

- No 
- About what percentage of your students have Internet access sufficient to continue learning at home?

- About what percentage of your students have computer access sufficient to continue learning at home?

- About what percentage of the learning that happened before the pandemic is still happening now for your students?

- If learning is still happening among your students, please describe how it is still happening?

- What distance learning websites or applications are you using to help communicate with your students?

- What distance learning websites or applications are you using to allow your students to submit work?

- What other websites or applications (if any) have you adopted to support student learning in response to the pandemic?

- What percentage of the websites or applications you are using were new to you before the pandemic?

- Check the learning management systems that you have been using.

- I used this learning management system before the pandemic

- I am using this learning management system now

- Blackboard

- D2L Brightspace

- Canvas

- Google Classroom

- Moodle

- Schoology

- Edmodo

- ITS Learning

- Other system

- If you are using a learning management system, please describe how you are using it to support learning.

- What strategies did you use to quickly gain knowledge about new distance learning websites and applications?

- What were the greatest difficulties you encountered when you prepared to teach students via distance learning?

- What kind of help do you wish you would have had as you prepared to support distance learning?

- Of the teaching practices and tools that you have adopted in response to the pandemic, which ones do you think you will continue to use once the pandemic is over?

Declarations We consulted extensively with the IRB at Mississippi State University who determined that our study was exempt from full IRB review. An IRB exemption was granted from the IRB of Mississippi State University. Informed consent was obtained from all individual participants included in the study. No funding was received for conducting this study. The authors have no financial or non-financial interests, or other conflicts of interest related to this study.
Conflict of Interest The authors have no relevant financial or nonfinancial interests to disclose. The authors have no conflicts of interest to declare that are relevant to the content of this article. We consulted extensively with the IRB at Mississippi State University who determined that our study was exempt from full IRB review. An IRB exemption was granted from the IRB of Mississippi State University.

Informed Consent Informed consent was obtained from all individual participants included in the study.

\section{References}

An, Y., \& Reigeluth, C. (2012). Creating technology-enhanced, learnercentered classrooms: K-12 teachers' beliefs, perceptions, barriers, and support needs. Journal of Digital Learning in Teacher Education, 28(2), 54-62.

Anderson, K. J., \& Minke, K. M. (2007). Parent involvement in education: Toward an understanding of parents' decision making. The Journal of Educational Research, 100(5), 311-323. https://doi.org/ 10.3200/JOER.100.5.311-323.

Barbour, M. K., McLaren, A., \& Zhang, L. (2015). It's not that tough: Students speak about their online learning experiences. Turkish Online Journal of Distance Education, 13(2), 226-241.

Bates, R. (2013). Institutional continuity and distance learning: A symbiotic relationship. Online Journal of Distance Learning Administration, 16(4).

Bauer, J. M., Hampton, K. N., Fernandez, L., \& Robertson, C. (2020). Overcoming Michigan's homework gap: The role of broadband Internet connectivity for student success and career outlooks (SSRN scholarly paper ID 3714752). Social Science Research Network. https://doi.org/10.2139/ssrn.3714752.

Butcher, J. (2020). Public-private virtual-school partnerships and federal flexibility for schools during COVID-19 (Mercatus center research paper series) [special edition policy brief]. Mercatus Center.

Creed, C., \& Morpeth, R. L. (2014). Continuity education in emergency and conflict situations: The case for using open, distance and flexible learning. Journal of Learning for Development, 1(3).

Czerniewicz, L. (2020). What we learnt from "going online" during university shutdowns in South Africa. PhilOnEdTech. https:// philonedtech.com/what-we-learnt-from-going-online-duringuniversity-shutdowns-in-south-africa/

Czerniewicz, L., Trotter, H., \& Haupt, G. (2019). Online teaching in response to student protests and campus shutdowns: Academics' perspectives. International Journal of Educational Technology in Higher Education, 16(1), 43-65. https://doi.org/10.1186/s41239019-0170-1.

Daoud, R., Starkey, L., Eppel, E., Vo, T. D., \& Sylvester, A. (2020). The educational value of internet use in the home for school children: A systematic review of literature. Journal of Research on Technology in Education, 1-22. https://doi.org/10.1080/15391523.2020. 1783402.

Duford, D. G. (2008). Perceptions of School Superintendents and a Community Task Force Regarding the Health, Pedagogical, Social, and Economic Policy and Planning Decisions for LongTerm School Closure Due to Pandemic Influenza-A MultiMethod Approach [doctoral dissertation]. St. John Fisher College.

Ertmer, P. A., \& Ottenbreit-Leftwich, A. T. (2010). Teacher technology change. Journal of Research on Technology in Education, 42(3), 255-284. https://doi.org/10.1080/15391523.2010.10782551.

Etherington, C. (2017). Five states require online learning credits for high school graduation. ELearningInside News. https://news. elearninginside.com/five-states-require-online-learning-creditshigh-school-graduation/ 
Fox, R. (2004). SARS epidemic: Teachers' experiences using ICTs. In R. Atkinson, C. McBeath, D. Jonas-Dwyer, \& R. Phillips (Eds.), Beyond the comfort zone: Proceedings of the 21st ASCILITE Conference (pp. 319-327). ASCILITE.

Francom, G. M. (2016). Barriers to technology use in large and small school districts. Journal of Information Technology Education: Research, 15, 577-591.

Hanssen, G. M., \& Rana, T. A. (2007, May). E-learning as part of disaster recovery planning. International Educational Technology Conference, Nicosia, Turkish Republic of Northern Cyprus https:// eric.ed.gov/?id=ED500138.

Hodges, C., Moore, S., Lockee, B., Trust, T., \& Bond, A. (2020). The difference between emergency remote teaching and online learning. Educause Review. https://er.educause.edu/articles/2020/3/thedifference-between-emergency-remote-teaching-and-onlinelearning

Howley, A., Wood, L., \& Hough, B. (2011). Rural elementary school teachers' technology integration. Journal of Research in Rural Education, 26(9), 1-13.

INEE. (2004). Minimum standards for education in emergencies, chronic crises and early reconstruction (p. 96). https://www.unicef.org/ violencestudy/pdf/min_standards_education_emergencies.pdf

Kopcha, T. J. (2012). Teachers' perceptions of the barriers to technology integration and practices with technology under situated professional development. Computers \& Education, 59(4), 1109-1121.

Laprairie, K. N., \& Hinson, J. M. (2006). When disaster strikes, move your school online. Journal of Educational Technology Systems, 35(2), 209-214. https://doi.org/10.2190/D154-XK20-7264-5013.

Liao, Y.-C., Ottenbreit-Leftwich, A., Karlin, M., Glazewski, K., \& Brush, T. (2017). Supporting change in teacher practice: Examining shifts of teachers' professional development preferences and needs for technology integration. Contemporary Issues in Technology and Teacher Education, 17(4), 522-548.

Mackey, J., Gilmore, F., \& Dabner, N. (2012). Blended learning for academic resilience in times of disaster or crisis. Journal of Online Teaching and Learning, 8(2), 122-135.
McLennan, K. L. (2006). Selected distance education disaster planning lessons learned from hurricane Katrina. Online Journal of Distance Learning Administration, 9(4) https://www.westga.edu/ distance/ ojdla/winter94/mclennan94.htm.

Reigeluth, C. M., Beatty, B., \& Myers, R. (2016). The learner-centered paradigm of instruction. In C. M. Reigeluth, B. Beatty, \& R. Myers (Eds.), Instructional-design theories and models: The learnercentered paradigm of education. Routledge.

Reigeluth, C. M., \& Karnopp, J. R. (2013). Reinventing schools: It's time to break the mold. Rowman \& Littlefield Education.

Rice, K. (2012). Making the move to K-12 online teaching: Researchbased strategies and practices. Pearson.

Ruggiero, D., \& Mong, C. J. (2015). The teacher technology integration experience: Practice and reflection in the classroom. Journal of Information Technology Education: Research, 14, 161-178.

Sundeen, T. H., \& Sundeen, D. M. (2013). Instructional technology for rural schools: Access and acquisition. Rural Special Education Quarterly, 32(2), 8-14.

Thomas, G. A., Morse, S. S., Alvarez, W., Soloff, L., Abramson, D. M., \& Redlener, I. E. (2007). The New York City principals pandemic flu survey: Are schools prepared? (p. 15). National Center for disaster preparedness.

Tull, S., Dabner, N., \& Ayebi-Arthur, K. (2017). Social media and elearning in response to seismic events: Resilient practices. Journal of Open Flexible and Distance Learning, 21(1), 63-76.

Wong, K. K., Shi, J., Gao, H., Zheteyeva, Y. A., Lane, K., Copeland, D., Hendricks, J., McMurray, L., Sliger, K., Rainey, J. J., \& Uzicanin, A. (2014). Why is school closed today? Unplanned K-12 school closures in the United States, 2011-2013. PLoS One, 9(12). https://doi.org/10.1371/journal.pone.0113755.

Publisher's Note Springer Nature remains neutral with regard to jurisdictional claims in published maps and institutional affiliations. 